\title{
BMJ Open A cross-sectional examination of the profile of chiropractors recruited to the Australian Chiropractic Research Network (ACORN): a sustainable resource for future chiropractic research
}

\author{
Jon Adams, ${ }^{1}$ Wenbo Peng, ${ }^{1}$ Amie Steel, ${ }^{1}$ Romy Lauche, ${ }^{1}$ Craig Moore, ${ }^{1}$ \\ Lyndon Amorin-Woods, ${ }^{2}$ David Sibbritt ${ }^{1}$
}

To cite: Adams J, Peng W, Steel A, et al. A cross-sectional examination of the profile of chiropractors recruited to the Australian Chiropractic Research Network (ACORN): a sustainable resource for future chiropractic research. BMJ Open 2017;7:e015830. doi:10.1136/ bmjopen-2017-015830

- Prepublication history and additional material for this paper are available online. To view, please visit the journal (http:// dx.doi.org/10.1136/bmjopen2017-015830)

Received 3 January 2017 Revised 21 July 2017 Accepted 9 August 2017

\section{CrossMark}

${ }^{1}$ Australian Research Centre in Complementary and Integrative Medicine (ARCCIM), Faculty of Health, University of Technology Sydney, Sydney, New South Wales, Australia

${ }^{2}$ School of Health Professions, Murdoch University, Murdoch, Australia

Correspondence to Distinguished Professor Jon Adams; Jon.Adams@uts.edu.au

\section{ABSTRACT}

Objectives The Australian Chiropractic Research Network (ACORN) practice-based research network (PBRN) cohort was established to provide sustainable infrastructure necessary to address lack of rigorous investigation and to bridge the research-practice gap focused on chiropractic care for future years. This paper presents the profile of chiropractors recruited to the ACORN PBRN, a nationally representative sample of chiropractors working in Australia.

Design Cross-sectional analysis of baseline data from a cohort study of chiropractors in Australia.

Setting All registered chiropractors in Australia were invited to participate in the ACORN study and those who completed a practitioner questionnaire and consent form were included in the PBRN cohort.

Participants A total of 1680 chiropractors (36\%) were recruited to the cohort database. The average age of the PBRN participants is 41.9 years and $63 \%$ are male. The vast majority of the PBRN participants hold a university degree.

Results General practitioners were identified as the most popular referral source for chiropractic care and low back pain and neck pain were the most common conditions 'often' treated by the PBRN chiropractors. The chiropractors in this PBRN cohort rated high velocity, low amplitude adjustment/manipulation/mobilisation as the most commonly used technique/method and soft tissue therapy as the most frequently employed musculoskeletal intervention in their patient management.

Conclusions The ACORN PBRN cohort constitutes the largest coverage of any single healthcare profession via a national voluntary PBRN providing a sustainable resource for future follow-up. The ACORN cohort provides opportunities for further nested substudies related to chiropractic care, chiropractors, their patients and a vast range of broader healthcare issues with a view to helping build a diverse but coordinated research programme and further research capacity building around Australian chiropractic.

\section{INTRODUCTION}

The chiropractic profession constitutes a common, well-established healthcare option
Strengths and limitations of this study

- The Australian Chiropractic Research Network (ACORN) practice-based research network (PBRN) project is the first national voluntary cohort study focusing on Australian chiropractic care, providing a variety of practice information about chiropractors both in the short term and long term.

- All registered chiropractors in Australia were invited to participate in the ACORN PBRN cohort, with $36 \%$ of the profession ( $n=1680$ ) signing up to the ACORN PBRN practitioner database.

- The substudy approach of the ACORN PBRN cohort provides a flexible model enabling investigation of a vast range of practice, practitioner and patientfocused issues of direct relevance to chiropractic and also other broader but related areas of the Australian healthcare system.

- One limitation of the ACORN PBRN practitioner database was the questionnaire content was restricted by a need to ensure least burden on respondents as possible but excluded topics can be the focus of future follow-up ACORN PBRN substudies.

in a number of countries, attracting good patient satisfaction especially for the management of musculoskeletal problems. ${ }^{12}$ In Australia, chiropractors are regulated under the National Registration Scheme ${ }^{3}$ and there were 4684 registered chiropractors practising in Australia in $2015 .{ }^{4}$ The number of services provided by Australian chiropractors has steadily increased in recent years ${ }^{56}$ and the ancillary benefit among Australians seeking help from chiropractors was \$A77 million in the June quarter $2016 .{ }^{7}$

The Australian Health Practitioner Regulation Agency (AHPRA) - the national agency regulating the chiropractic profession among other professions in Australia-continues 
to place an increasing evidence-based focus on chiropractic clinical practice. ${ }^{8}$ Moreover, the relatively small number of PhDs/early career researchers in chiropractic and the significant research-practice gap in chiropractic enquiry $^{9-11}$ have been met with calls from within the Australian chiropractic profession to develop a more sustainable research culture.

One well-developed strategy by which to address the research-practice gap in healthcare (including chiropractic) is via developing practice-based research networks (PBRNs). ${ }^{12} 13$ A PBRN is a group of practices affiliated together with professional academic institutions, in order to facilitate research studies designed for addressing research questions around daily routine care. ${ }^{14-16}$ One significant advantage of establishing a PBRN is an ability for healthcare practitioners to directly contribute to the development of research in their clinical areas of interest, as well as to facilitate researchers to undertake studies focusing on meaningful research questions relevant to clinical practice. ${ }^{14} \mathrm{PBRNs}$ also provide significant opportunities for further nested substudies which can focus on efficacy, safety and use of healthcare among other related issues. ${ }^{12} 14$ PBRN projects have been established across a range of healthcare fields including in primary care, dentistry and pharmacy ${ }^{17-19}$ and previous PBRN projects have employed various research methods and designs including (but not restricted to) clinical trials, survey designs, qualitative studies, practice change interventions and cost-effectiveness analyses. ${ }^{1420}$

The Australian Chiropractic Research Network (ACORN) PBRN project (www.acorn-arccim.com) is the first national voluntary PBRN to focus exclusively on chiropractic care and received official registration as an international PBRN with the Agency for Healthcare Research and Quality PBRN Resource Centre in 2015. ${ }^{21}$ The ACORN PBRN programme established in 2014 and funded by the Chiropractors' Association of Australia (CAA) is independently designed and conducted by senior health researchers at the Australian Research Centre in Complementary and Integrative Medicine, University of Technology Sydney.

The ACORN PBRN cohort facilitates the investigation of research questions regarding chiropractic best practice, cost-effectiveness and safety among many others. The purpose of this cohort is to establish a substantial national infrastructure providing practice-based and practitioner-relevant chiropractic research, boost research activity and capacity for the chiropractic profession, help bridge the research-practice gap in chiropractic investigation, encourage chiropractors and researchers to conduct substudies based on the ACORN PBRN database and advance critical rigorous scientific methods to conduct multidisciplinary and mid-term/long-term investigation in chiropractic care. The ACORN project is a long-term, prospective cohort PBRN which has clear and active plans for future study and substudy work. The ACORN project has been established with a long-term future in mind to generate ongoing research and research capacity building and to help answer a wide number of research questions across a vast range of topics not only relating directly to chiropractic care but also regarding back pain, spine health and the treatment of other conditions across the healthcare system more broadly. Furthermore, there are currently active plans to follow-up the ACORN baseline questionnaire in the near future and to repeat such a follow-up exercise in regard to the ACORN members over coming years as means of maintaining this baseline database for further national investigation around a wide range of research issues. At time of writing (May 2017), three follow-up ACORN substudies have received approval from the ACORN Steering Committee and are either completed or in progress. Several other substudies are currently in development or under consideration by the ACORN Steering Committee. To be specific, approved substudies are investigating the management of patients with headache disorders by Australian chiropractors, the details of nutritional guidance provided by chiropractors to their patients and the research priorities for the profession as perceived by chiropractors.

The aim of this paper is to overview the baseline data from the ACORN PBRN cohort focusing on the practitioner characteristics, practice characteristics and clinical management of those chiropractors recruited. We offer this description of the ACORN PBRN cohort in order to encourage and assist those who may seek to undertake future secondary analyses of the ACORN database and/ or design and undertake a nested substudy drawing on the ACORN project at a later date.

\section{METHODS}

\section{Recruitment}

All registered chiropractors in Australia were invited to participate in the ACORN PBRN cohort. The ACORN PBRN research team invested over 12 months in designing and promoting the initiative prior to the recruitment period (from March 2015 to July 2015). Branding, a multifaceted promotional campaign, specific questionnaire design, invitation pack design and a number of distribution approaches were all employed to recruit chiropractors to the ACORN PBRN. ${ }^{22}$ The details of the strategies employed to recruit chiropractors to the ACORN PBRN can be found elsewhere. ${ }^{22}$ In brief, in order to achieve a nationally representative cohort, the largest national chiropractic health body (CAA) and another national professional chiropractic body (Chiropractic and Osteopathic College of Australia (COCA)) participated in promoting the ACORN PBRN. Group emails were forwarded through these two associations' networks to all of their members at regular intervals. Both online and hard-copy questionnaires and consent forms were distributed. Completion and return of the ACORN baseline questionnaire constituted implied consent in line with University of Technology Sydney ethics guidelines. For a chiropractor to become a member/participant in the broader, ongoing ACORN project and to be recruited 
4684 Australian registered chiropractors

Missing data: non-respondents to the survey

\section{Australian registered chiropractors}

Missing data: participants do not want to be involved in the PBRN cohort

1680 Australian registered chiropractors
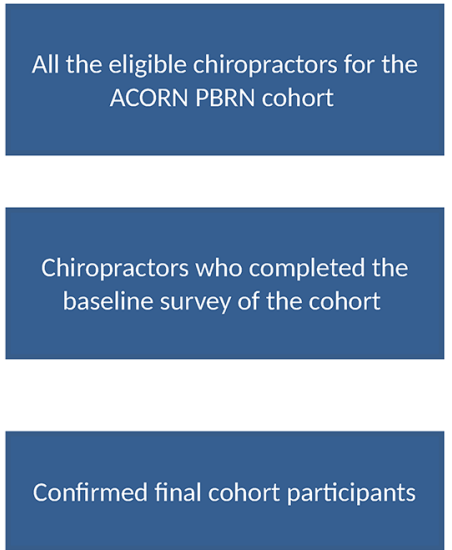

Figure 1 The Australian Chiropractic Research Network practice-based research network (ACORN PBRN) cohort diagram.

to the ACORN, baseline database required respondents to complete a separate consent form clearly outlining their rights and conditions of ongoing participation and inclusion on the ACORN database. Only those respondents who completed the questionnaire AND provided additional written consent were recruited to the ACORN PBRN cohort, were added to the ACORN baseline database and are thereby available for future substudy recruitment. The consenting ACORN PBRN members are free to further consent or not consent to any additional substudy recruitment invitations on a substudy by substudy basis. However, these ACORN PBRN members have consented to be contacted and invited for recruitment for any relevant substudies through time. In addition, as Continuing Professional Development (CPD) is one of the prerequisites for all registered chiropractors to renew their registration every year, CPD credits were offered to the chiropractors participating in the cohort. A number of merchandise relevant to the ACORN project (eg, banners and postcards) were distributed via the Australian chiropractic community and a one-off promotional news item was distributed via the AHPRA to recruit more chiropractors, in particular non-members of the CAA and COCA.

At the time of recruitment, there were 4684 registered chiropractors in Australia, and 1680 chiropractors completed the consent form (36\% response rate) thereby signing up to the ACORN PBRN practitioner database (figure 1). The ACORN PBRN sample has been shown to be broadly representative of the chiropractic profession in Australia with regard to a number of key indicators demonstrated in the AHPRA chiropractic database including age (ACORN PBRN/AHPRA: <30 years $(16 \% / 18 \%)$, $30-39$ years $(31 \% / 30 \%), 40-49$ years $(26 \% / 26 \%), 50-59$ years $(18 \% / 16 \%)$ and $>60$ years $(9 \% / 10 \%), \mathrm{p}=0.134)$, gender (male/female: $63 \% / 37 \%$ in both ACORN PBRN and AHPRA databases, $\mathrm{p}=0.956$ ) and location (ACORN PBRN/AHPRA: New South Wales $(34 \% / 35 \%)$, Victoria (25\%/26\%), Queensland (15\%/16\%), Western Australia $(13 \% / 13 \%)$, South Australia $(9 \% / 7 \%)$, Australian Capital Territory $(2 \% / 1 \%)$ and both Tasmania and Northern Territory are $1 \%, \mathrm{p}=0.023) .{ }^{22}$ A total of $58 \%$ of the ACORN PBRN participants were identified in the first month of the recruitment period, and significant increases in response numbers generally occurred following the distribution of a series of group emails to CAA/COCA members. The ACORN PBRN has been approved by the University of Technology Sydney Human Ethics Committee (approval no 2014000027).

\section{Questionnaire items}

The ACORN PBRN practitioner questionnaire administered as part of the ACORN PBRN invitation and recruitment pack covered 21 items including questions around practitioner characteristics, practice characteristics and clinical management. Extensive pilot testing of the questionnaire design was undertaken with 10 chiropractors in the field prior to official recruitment and a small number of formatting and wording revisions were undertaken as a result.

As part of the ACORN PBRN practitioner questionnaire (see online supplementary appendix 1), chiropractors were questioned about their age and gender, to indicate whether they were currently working in private chiropractic practice and to identify the number of years they have been in private practice. The participants were also asked to provide details of their highest chiropractic professional qualification obtained.

The ACORN PBRN questionnaire included items examining average patient care hours per week, average patient visits per week, practice location information, the frequency of diagnostic imaging use and use of electronic records. Participants were questioned about whether any other health professionals also worked in their practice and their professional referral relationship with these health practitioners. Participants were further asked to identify imaging facilities or scanning tools on site in their clinical practice. Participants were questioned with regard to the frequency with which they discuss a range of common health issues as part of their patient care/ management plans. In addition, participants were questioned about the frequency with which they treat specific patient groups.

Chiropractors in the ACORN PBRN sample were questioned about the frequency with which they treat patients 
who present with a number of health conditions and to identify which chiropractic techniques/methods as well as musculoskeletal interventions they employ in the management of their patients.

\section{Statistical analyses}

All data were imported into the statistical software Stata 13.1. Means and SDs were assessed to describe the sample of this ACORN PBRN database. The frequencies (percentages) with which chiropractors treat patient subgroups, with which chiropractors treat patients who present with a condition, with which chiropractors employ techniques in their patient care, with which chiropractors employ musculoskeletal interventions in their patient care and with which chiropractors discuss health issues as part of their patient care plan were examined.

\section{RESULTS}

\section{Chiropractic practitioner characteristics}

The average age of the ACORN PBRN practitioners is 41.9 ( $\mathrm{SD}=12.0$ ) years, with $62.9 \%$ being male. In terms of formal chiropractic qualifications, $2.1 \%$ of practitioners attained a diploma, $0.8 \%$ attained an advanced diploma, $34.9 \%$ attained a bachelor (or double bachelor) degree, $29.5 \%$ attained a doctor of chiropractic, $32.0 \%$ attained a masters degree and $0.8 \%$ attained a doctoral degree. On average, the practitioners have worked for $15.6(\mathrm{SD}=11.2)$ years in private practice. The majority of the participants report being members of CAA $(68.0 \%)$ with $19.8 \%$ being members of COCA and $7.7 \%$ being members of both. Over the last 12 months, other than being active in private practice, $7.2 \%$ of the respondents report being involved in university teaching, $6.1 \%$ report being involved in research, $11.1 \%$ report being involved in clinical supervision, $18.7 \%$ report being involved in volunteer work and $20.1 \%$ report being involved in professional organisation activities. Only $7.0 \%$ of the participants routinely consult patients in a language other than English.

\section{Practice characteristics}

The ACORN PBRN practitioners report that, on an average week, they provide $27.3(\mathrm{SD}=12.8)$ patient care hours, comprising $87.5(\mathrm{SD}=56.3)$ patient visits. More than a quarter $(25.2 \%)$ of ACORN practitioners have more than one practice location, but the majority $(75.9 \%)$ practice in an urban area, with only $9.6 \%$ practising in a rural area and $17.1 \%$ in a remote area. Figure 2 shows the distribution of ACORN PBRN chiropractors in each state/territory of Australia. A number of ACORN PBRN chiropractors practice in both urban and rural $(n=33)$ or both urban and remote $(n=49)$ or both rural and remote settings $(n=17)$.

The majority of ACORN PBRN practitioners (66.1\%) have at least one other health professional working in their practice location, including: another chiropractor (59.9\%), a psychologist or counsellor $(12.2 \%)$, a podiatrist (9.6\%), a physiotherapist (9.3\%), an exercise physiologist (6.6\%), a general practitioner (GP) $(5.9 \%)$, a medical specialist $(2.5 \%)$, an occupational therapist $(2.5 \%)$ or an 'other' health professional (32.5\%). The ACORN PBRN chiropractors report having professional referral relationships (ie, sending and/or receiving referrals) with a range 
Table 1 Frequency with which practitioners treat patient subgroups

\begin{tabular}{|c|c|c|c|}
\hline \multirow[b]{2}{*}{ Patient subgroup } & \multicolumn{3}{|c|}{ Frequency } \\
\hline & Never/rarely & Sometimes & Often \\
\hline Children (up to 3 years) & $36 \%$ & $34 \%$ & $30 \%$ \\
\hline Children (4-18years) & $8 \%$ & $39 \%$ & $53 \%$ \\
\hline $\begin{array}{l}\text { Older people (65years } \\
\text { and over) }\end{array}$ & $4 \%$ & $23 \%$ & $73 \%$ \\
\hline $\begin{array}{l}\text { Aboriginal and Torres } \\
\text { Strait Islander people }\end{array}$ & $83 \%$ & $15 \%$ & $2 \%$ \\
\hline Pregnant women & $16 \%$ & $47 \%$ & $37 \%$ \\
\hline $\begin{array}{l}\text { Athletes or sports } \\
\text { people }\end{array}$ & $7 \%$ & $42 \%$ & $51 \%$ \\
\hline $\begin{array}{l}\text { People with work- } \\
\text { related injuries }\end{array}$ & $21 \%$ & $43 \%$ & $36 \%$ \\
\hline $\begin{array}{l}\text { People with traffic- } \\
\text { related injuries }\end{array}$ & $37 \%$ & $49 \%$ & $14 \%$ \\
\hline $\begin{array}{l}\text { People receiving } \\
\text { postsurgical } \\
\text { rehabilitation }\end{array}$ & $57 \%$ & $36 \%$ & $7 \%$ \\
\hline $\begin{array}{l}\text { Non-English speaking } \\
\text { ethnic groups }\end{array}$ & $77 \%$ & $17 \%$ & $6 \%$ \\
\hline
\end{tabular}

of practitioners, including: a GP $(56.3 \%)$, a podiatrist (40.1\%), a physiotherapist (31.6\%), a medical specialist $(16.2 \%)$, an exercise physiologist $(15.8 \%)$, a psychologist or counsellor $(14.3 \%)$, an occupational therapist $(8.4 \%)$ or an 'other' health professional $(22.0 \%)$.

Electronic records are used by $45.4 \%$ of the ACORN PBRN practitioners, with $35.2 \%$ of the ACORN PBRN sample using such electronic records for initial history, $41.8 \%$ for subsequent patient visits and $36.4 \%$ for examination findings. Diagnostic imaging is used by $47.9 \%$ of the ACORN PBRN chiropractors on an 'often' basis, $39.7 \%$ on a 'sometimes' basis and rarely or never by $12.4 \%$ of the sample. The majority of the ACORN PBRN chiropractors $(67.2 \%)$ do not have any imaging facilities or scanning tools on site, but of those who do, $45.8 \%$ have an X-ray machine, $13.7 \%$ have a thermograph, $13.2 \%$ have a SEMG devise, $9.5 \%$ have an MRI machine and $8.2 \%$ have an ultrasound machine.

\section{Clinical management}

The ACORN PBRN chiropractors reported the frequency with which they treat specific patient subgroups (table 1). Older people (aged 65 years and over) and children (aged 4-18 years) are treated on an 'often' basis by $73 \%$ and $53 \%$ of practitioners, respectively. The majority of ACORN PBRN practitioners report as 'never' or 'rarely' treating Aboriginal and Torres Strait Islander people $(83 \%)$ or people from non-English speaking ethnic groups $(77 \%)$.

Table 2 shows the frequency with which the ACORN PBRN chiropractors treat patients that present with particular conditions, including neck pain, thoracic pain, low back pain, lower and upper limb musculoskeletal
Table 2 Frequency with which practitioners treat patients that present with a condition

\begin{tabular}{|c|c|c|c|}
\hline \multirow[b]{2}{*}{ Condition } & \multicolumn{3}{|c|}{ Frequency } \\
\hline & Never/rarely & Sometimes & Often \\
\hline Neck pain (axial) & $1 \%$ & $6 \%$ & $93 \%$ \\
\hline $\begin{array}{l}\text { Neck pain (referred/ } \\
\text { radicular) }\end{array}$ & $4 \%$ & $34 \%$ & $62 \%$ \\
\hline Thoracic pain (axial) & $1 \%$ & $14 \%$ & $85 \%$ \\
\hline $\begin{array}{l}\text { Thoracic pain (referred/ } \\
\text { radicular) }\end{array}$ & $17 \%$ & $37 \%$ & $46 \%$ \\
\hline Low back pain (axial) & $1 \%$ & $4 \%$ & $95 \%$ \\
\hline $\begin{array}{l}\text { Low back pain (referred/ } \\
\text { radicular) }\end{array}$ & $2 \%$ & $17 \%$ & $81 \%$ \\
\hline $\begin{array}{l}\text { Lower limb } \\
\text { musculoskeletal } \\
\text { disorders }\end{array}$ & $5 \%$ & $35 \%$ & $60 \%$ \\
\hline $\begin{array}{l}\text { Upper limb } \\
\text { musculoskeletal } \\
\text { disorders }\end{array}$ & $4 \%$ & $33 \%$ & $63 \%$ \\
\hline Postural disorders & $7 \%$ & $31 \%$ & $62 \%$ \\
\hline $\begin{array}{l}\text { Degenerative spine } \\
\text { conditions }\end{array}$ & $7 \%$ & $29 \%$ & $64 \%$ \\
\hline Headache disorders & $1 \%$ & $12 \%$ & $87 \%$ \\
\hline Migraine disorders & $6 \%$ & $41 \%$ & $53 \%$ \\
\hline $\begin{array}{l}\text { Spinal health } \\
\text { maintenance/prevention }\end{array}$ & $5 \%$ & $21 \%$ & $74 \%$ \\
\hline $\begin{array}{l}\text { Non-musculoskeletal } \\
\text { disorders }\end{array}$ & $42 \%$ & $28 \%$ & $30 \%$ \\
\hline
\end{tabular}

disorders, postural disorders, degenerative spine conditions, headache/migraine disorders, spinal health maintenance/prevention and non-musculoskeletal disorders. The majority of practitioners 'often' treat patients presenting with all of these conditions with the most common being low back pain (axial) (95\%), neck pain (axial) (93\%), headache disorders (87\%) and thoracic pain (axial) $(85 \%)$.

The ACORN PBRN chiropractors report using a variety of techniques/methods in their patient management, and the frequency of such use is presented in table 3. Most ACORN PBRN practitioners (83\%) employ high velocity, low amplitude adjustment/manipulation/mobilisation on an 'often' basis. Other common techniques/methods used on an 'often' basis include extremity manipulation (59\%), drop-piece techniques/ Thomson or similar (55\%) and instrument adjusting $(53 \%)$.

Table 4 shows the musculoskeletal interventions employed by the ACORN PBRN chiropractors in their patient management. Nearly two-thirds $(66 \%)$ of the chiropractors employ soft tissue therapy, trigger point therapy, massage therapy or stretching on an 'often' basis, while $50 \%$ report using specific exercise therapy/rehabilitation/injury taping on an 'often' basis. 
Table 3 Frequency with which practitioners employ techniques/methods in their patient management

\begin{tabular}{llll}
\hline & \multicolumn{3}{c}{ Frequency } \\
\cline { 2 - 4 } Technique/method & $\begin{array}{l}\text { Never/ } \\
\text { rarely }\end{array}$ & Sometimes & Often \\
\hline $\begin{array}{l}\text { Drop-piece techniques/ } \\
\text { Thomson or similar }\end{array}$ & $25 \%$ & $20 \%$ & $55 \%$ \\
$\begin{array}{l}\text { Biomechanical pelvic } \\
\text { blocking/sacro-occipital } \\
\text { technique }\end{array}$ & $31 \%$ & $24 \%$ & $45 \%$ \\
\hline $\begin{array}{l}\text { Instrumental adjusting } \\
\text { Chiropractic biophysics }\end{array}$ & $22 \%$ & $25 \%$ & $53 \%$ \\
\hline $\begin{array}{l}\text { High velocity, low } \\
\text { amplitude adjustment/ } \\
\text { manipulation/mobilisation }\end{array}$ & $8 \%$ & $5 \%$ & $4 \%$ \\
\hline $\begin{array}{l}\text { Applied kinesiology } \\
\text { Flexion distraction }\end{array}$ & $70 \%$ & $9 \%$ & $83 \%$ \\
\hline $\begin{array}{l}\text { Functional neurology } \\
\text { Extremity manipulation }\end{array}$ & $87 \%$ & $14 \%$ & $16 \%$ \\
\hline
\end{tabular}

The ACORN PBRN chiropractors report discussing a range of health issues with patients as part of their care/ management plans (table 5). Substantial numbers of the ACORN PBRN chiropractors would 'often' discuss physical activity/fitness (86\%), diet/nutrition (51\%) and occupational health and safety $(42 \%)$ and would 'sometimes' discuss smoking/drugs/alcohol (48\%), medications $(47 \%)$, nutritional supplements $(42 \%)$ and pain counselling $(38 \%)$ as part of their patient care.

\section{DISCUSSION}

Descriptive analyses of the ACORN PBRN cohort reveal a number of interesting findings regarding Australian chiropractic and our PBRN cohort provides important

Table 4 Frequency with which practitioners employ musculoskeletal interventions in their patient management

\begin{tabular}{|c|c|c|c|}
\hline \multirow{2}{*}{$\begin{array}{l}\text { Musculoskeletal } \\
\text { intervention }\end{array}$} & \multicolumn{3}{|c|}{ Frequency } \\
\hline & Never/rarely & Sometimes & Often \\
\hline $\begin{array}{l}\text { Dry needling or } \\
\text { acupuncture }\end{array}$ & $75 \%$ & $11 \%$ & $14 \%$ \\
\hline $\begin{array}{l}\text { Soft tissue therapy, } \\
\text { trigger point therapy, } \\
\text { massage therapy, } \\
\text { stretching }\end{array}$ & $14 \%$ & $20 \%$ & $66 \%$ \\
\hline $\begin{array}{l}\text { Electromodalities } \\
\text { (eg, transcutaneous } \\
\text { electrical nerve } \\
\text { stimulation) }\end{array}$ & $77 \%$ & $13 \%$ & $10 \%$ \\
\hline Heat/cryotherapy & $57 \%$ & $26 \%$ & $17 \%$ \\
\hline Orthotics (foot care) & $65 \%$ & $25 \%$ & $10 \%$ \\
\hline $\begin{array}{l}\text { Specific exercise } \\
\text { therapy/rehabilitation/ } \\
\text { injury taping }\end{array}$ & $19 \%$ & $31 \%$ & $50 \%$ \\
\hline
\end{tabular}

Table 5 Frequency with which practitioners discuss health issues as part of their care/management plans

\begin{tabular}{|c|c|c|c|}
\hline \multirow[b]{2}{*}{ Health issues } & \multicolumn{3}{|c|}{ Frequency } \\
\hline & Never/rarely & Sometimes & Often \\
\hline Diet/nutrition & $10 \%$ & $39 \%$ & $51 \%$ \\
\hline Smoking/drugs/alcohol & $27 \%$ & $48 \%$ & $25 \%$ \\
\hline Physical activity/fitness & $1 \%$ & $13 \%$ & $86 \%$ \\
\hline $\begin{array}{l}\text { Occupational health } \\
\text { and safety }\end{array}$ & $17 \%$ & $41 \%$ & $42 \%$ \\
\hline Pain counselling & $37 \%$ & $38 \%$ & $25 \%$ \\
\hline Nutritional supplements & $20 \%$ & $42 \%$ & $38 \%$ \\
\hline Medications & $29 \%$ & $47 \%$ & $24 \%$ \\
\hline
\end{tabular}

research opportunities for substudies addressing significant gaps in chiropractic clinical practice. For example, our analysis shows that the vast majority of the ACORN PBRN chiropractors hold a university degree while only $0.8 \%$ of them have been awarded a PhD degree. The valuable cohort substudy opportunities for postgraduate level projects nested within the ACORN PBRN will more easily allow those who are in clinical practice to now not only undertake PhD study but also contribute to future studies focused on understanding and where necessary improving the delivery of patient care. Additionally, the further participation in research of those who are clinically active via this PBRN practitioner cohort will help strengthen the broader research capacity and research engagement of the chiropractic profession in Australia (areas previously identified as requiring attention). ${ }^{9}{ }^{23}$

Many of the chiropractors included in the ACORN PBRN cohort maintain a variety of professional referral relationships. The cohort database is therefore an ideal platform for substudies exploring the interprofessional relationships between chiropractors and other healthcare practitioners. For example, with regard to patients with headache who consult chiropractors, a future substudy may focus on whom these patients have sought help beyond chiropractic and in which order of practitioner use (from a range of conventional physicians, allied health practitioners and other CAM practitioners) these patients have sought help. Further, this substudy may also examine the associations between the severity and changes in the patients' condition and their order of consultation (ie, who they first consult and the order of consultation with subsequent and existing providers). Indeed, no study undertaken in Australia to date has provided detailed information on the referral relationships with other health providers from within the Australian chiropractic care setting. Such potential substudies focusing on detailed chiropractic interprofessional relationships can assist chiropractors and other health practitioners in effectively communicating and collaborating with each other (as well as with their shared patients) 
in order to help ensure safe, effective and coordinated care.

Analyses of the ACORN PBRN cohort sample demonstrate that various kinds of musculoskeletal problems are the most commonly presented conditions treated by chiropractors and indicate a number of common therapies/ techniques frequently used by chiropractors in Australia. Drawing on the significant research infrastructure of the ACORN PBRN cohort database, a series of substudies examining a wide range of frequently used diagnostic procedures, treatment outcome measures and chiropractic therapies/techniques for certain symptoms and conditions are warranted to help critically evaluate chiropractic treatment outcomes. For instance, the ACORN PBRN cohort is well suited to facilitating substudies designed to compare the efficacy of two different interventions for the same condition (eg, comparing soft tissue therapy to trigger point therapy for low back pain) and to examine the efficacy of one technique for the treatment of two relevant conditions (eg, measuring the high velocity, low amplitude adjustment for neck pain as well as low back pain), as well as to further examine these research questions in different patient subgroups (eg, investigating the efficacy of the therapeutic interventions more commonly used by chiropractors for people older than 65 years with low back pain).

In addition, future ACORN PBRN substudies may include examinations of the prevalence of specific musculoskeletal interventions (eg, soft tissue therapy and trigger point therapy) for a range of musculoskeletal conditions (eg, lower limb pain and upper limb pain) among varied patient subgroups (eg, those with work-related injuries or traffic-related injuries), the reasons for the use of this intervention in the management of the selected musculoskeletal condition and the profile of chiropractors who use such an intervention for patients with this selected musculoskeletal condition. Another worthwhile area which remains under-researched is the cost-effectiveness of specific chiropractic techniques and treatments and this is again an area where the ACORN PBRN cohort can facilitate further rigorous study. More information on the economic and clinical value of specific areas of chiropractic care drawing on the ACORN PBRN cohort can provide important insights for policy-makers and other healthcare decision-makers in their goal to provide cost-effective services.

There are some limitations to our study. First, the ACORN PBRN practitioner questionnaire was self-reported. While this feature does mean that our findings are open to recall bias (relying on the chiropractors correctly recalling the details they report), this is not an unusual feature of survey-based data collection and the findings from other long-standing studies has supported the use of self-report measures for clinical and research purposes. ${ }^{24}$ This design feature of the ACORN PBRN practitioner questionnaire was developed in response to the challenge of establishing a PBRN in Australian chiropractic based on a unified patient record management system. ${ }^{22}$ Second, the ACORN PBRN practitioner questionnaire content was designed to be as least demanding and time-consuming as possible and with the specific aim of providing quality baseline data for the PBRN database. As such, other topics worthy of examination and focus (including issues where fieldwork will require direct patient-focused data from medical records, etc) are not accommodated in the ACORN PBRN questionnaire due to space restrictions. Nevertheless, such additional topics can be the focus of future follow-up ACORN PBRN substudies.

Nevertheless, the ACORN PBRN cohort constitutes the largest coverage of any single healthcare profession via a national voluntary PBRN to date ${ }^{25-27}$ and the cohort is representative of the national Australian chiropractic profession on a number of key indicators. Follow-up repeat of the ACORN baseline questionnaire in the near future also ensures a sustainable resource for further national investigation around a wide range of research issues both of direct relevance to or related to chiropractic and the wider healthcare system. In addition, a substudy PBRN approach, a novel feature of the ACORN PBRN design used to recruit the ACORN PBRN cohort, ${ }^{22}$ represents an excellent opportunity to facilitate a diverse range of research projects through time that do not directly rely and are not restricted by any initial data capture. Instead, a substudy approach provides the flexible model necessary to enable future investigation of a vast range of practice, practitioner and patient-focused issues and the ACORN PBRN cohort constitutes a flexible sustainable resource for not only undertaking nested substudies but also for helping build a strong coordinated research programme and grow research capacity in Australian chiropractic.

\section{CONCLUSION}

The recruited ACORN PBRN cohort constitutes a significant sustainable resource with which to facilitate further coordinated enquiry into different aspects of chiropractic care and with which to build a sustainable research culture focused on chiropractic for the benefit of policy-makers, practitioners, patients and safe, effective patient care. The ACORN PBRN cohort offers chiropractors and researchers a significant opportunity to undertake impactful research in a wide range of important areas, many of which may narrow the research-practice gap and reinforce a greater commitment to the advancement of evidence-based chiropractic practice.

Acknowledgements We thank all the chiropractors who consented to participate in the ACORN PBRN cohort.

Contributors All authors contributed to planning this ACORN PBRN cohort paper and approved the final version of the manuscript. JA and DS designed the research study. JA, DS, AS, CM and LA-W contributed to the data collection, and DS analysed the data. WP wrote the first draft. JA and DS implemented the critical revision of the manuscript. All authors provided final editing and approval of the manuscript.

Funding This work was supported by the Chiropractors' Association of Australia. The research reported in this paper was independently designed and conducted by the ACORN Project team. 
Competing interests None declared.

Patient consent Obtained.

Ethics approval The ACORN PBRN has been approved by the University of Technology Sydney Human Ethics Committee (approval no 2014000027).

Provenance and peer review Not commissioned; externally peer reviewed.

Data sharing statement № additional data are available.

Open Access This is an Open Access article distributed in accordance with the Creative Commons Attribution Non Commercial (CC BY-NC 4.0) license, which permits others to distribute, remix, adapt, build upon this work non-commercially, and license their derivative works on different terms, provided the original work is properly cited and the use is non-commercial. See: http://creativecommons.org/ licenses/by-nc/4.0/

(c) Article author(s) (or their employer(s) unless otherwise stated in the text of the article) 2017. All rights reserved. No commercial use is permitted unless otherwise expressly granted.

\section{REFERENCES}

1. Xue CCL, Zhang AL, Lin V, et al. Acupuncture, chiropractic and osteopathy use in Australia: a national population survey. BMC Public Health 2008;8:105.

2. Meeker WC, Haldeman S. Chiropractic: a profession at the crossroads of mainstream and alternative medicine. Ann Intern Med 2002;136:216-27.

3. Australian Health Practitioner Regulation Agency. National Boards of Australia 2016. https://www.ahpra.gov.au/ (accessed 31 May 2016).

4. Chiropractic Board of Australia. Statistics 2015. http://www. chiropracticboard.gov.au/About-the-Board/Statistics.aspx (accessed 10 June 2016).

5. Engel RM, Brown BT, Swain MS, et al. The provision of chiropractic, physiotherapy and osteopathic services within the Australian private health-care system: a report of recent trends. Chiropr Man Therap 2014;22:3.

6. Adams J, Lauche R, Peng W, et al. A workforce survey of Australian chiropractic: the profile and practice features of a nationally representative sample of 2,005 chiropractors. BMC Complement Altern Med 2017;17:14.

7. Australian Prudential Regulation Authority. Private health insurance quarterly statistics. http://www.apra.gov.au/PHI/Publications/ Documents/1608-QSR-20160630.pdf (accessed 16 Aug 2016).

8. Chiropractic Board of Australia. Codes and guidelines 2016. http:// www.chiropracticboard.gov.au/Codes-guidelines.aspx (accessed 26 Apr 2016).

9. Eaton S. The Australasian College of Chiropractors' research summit: investigating the significance of strategic research for the profession. Chiropractic Journal of Australia 2011;41:2

10. Stuber K, Bussières A, Gotlib A. Chiropractic research capacity in Canada in 2008. J Can Chiropr Assoc 2009;53:78-86.
11. Rubinstein SM, Bolton J, Webb AL, et al. The first research agenda for the chiropractic profession in Europe. Chiropr Man Therap 2014;22:9.

12. Agency for Healthcare Research and Quality. Practice-based research networks 2016. https://pbrn.ahrq.gov/ (accessed 19 Jul 2016).

13. Bussières $A$, Côté $P$, French $S$, et al. Creating a chiropractic practicebased research network (PBRN): enhancing the management of musculoskeletal care. J Can Chiropr Assoc 2014;58:8-15.

14. Davis MM, Keller S, DeVoe JE, et al. Characteristics and lessons learned from practice-based research networks (PBRNs) in the United States. J Healthc Leadersh 2012;4:107-16.

15. Gilbert GH, Richman JS, Gordan VV, et al. Lessons learned during the conduct of clinical studies in the dental PBRN. J Dent Educ 2011;75:453-65.

16. Graham DG, Spano MS, Stewart TV, et al. Strategies for planning and launching PBRN research studies: a project of the Academy of Family Physicians National Research Network (AAFP NRN). J Am Board Fam Med 2007;20:220-8.

17. Maclaughlin EJ, Ardery G, Jackson EA, et al. Institutional review board barriers and solutions encountered in the Collaboration Among Pharmacists and Physicians to Improve Outcomes Now Study: a national multicenter practice-based implementation trial. Pharmacotherapy 2013;33:902-11.

18. Gibson K, Szilagyi P, Swanger CM, et al. Physician perspectives on incentives to participate in practice-based research: a greater rochester practice-based research network (GR-PBRN) study. J Am Board Fam Med 2010;23:452-4

19. Gilbert GH, Williams OD, Korelitz JJ, et al. Purpose, structure, and function of the United States National Dental Practice-Based Research Network. J Dent 2013;41:1051-9.

20. Mays GP, Hogg RA, Castellanos-Cruz DM, et al. Public health research implementation and translation: evidence from practicebased research networks. Am J Prev Med 2013;45:752-62.

21. Adams J, Steel A, Chang S, et al. Helping address the national research and research capacity needs of Australian chiropractic: introducing the Australian Chiropractic Research Network (ACORN) project. Chiropr Man Therap 2015;23:12.

22. Adams J, Steel A, Moore C, et al. Establishing the ACORN national practitioner database: strategies to recruit practitioners to a national practice-based research network. J Manipulative Physiol Ther 2016.

23. Adams J, Broom A, Jennaway M. Qualitative methods in chiropractic research: one framework for future inquiry. J Manipulative Physiol Ther 2008;31:455-60.

24. Reuben DB, Siu AL, Kimpau S. The predictive validity of self-report and performance-based measures of function and health. $J$ Gerontol 1992:47:M106-M110.

25. Magin PJ, Marshall MJ, Goode SM, et al. How generalisable are results of studies conducted in practice-based research networks? A cross-sectional study of general practitioner demographics in two New South Wales networks. Med J Aust 2011;195:210-3.

26. Nixdorf DR, Law AS, Look JO, et al. Large-scale clinical endodontic research in the National Dental Practice-Based Research Network: study overview and methods. J Endod 2012;38:1470-8.

27. Galliher JM, Bonham AJ, Dickinson LM, et al. Representativeness of PBRN physician practice patterns and related beliefs: the case of the AAFP National Research Network. Ann Fam Med 2009;7:547-54. 